\title{
Determination of Organic Acids in Fruit and Vegetable Juices Using Capillary Electrophoresis
}

\author{
Viktoria V. Sursyakova*a, \\ Galina V. Burmakina ${ }^{\mathrm{a}, \mathrm{b}}$ and Anatoly I. Rubaylo ${ }^{\mathrm{a}, \mathrm{b}, \mathrm{c}}$ \\ anstitute of Chemistry and Chemical Technology SB RAS \\ 50/24 Akademgorodok, Krasnoyarsk, 660036, Russia \\ ${ }^{b}$ Siberian Federal University \\ 79 Svobodny, Krasnoyarsk, 660041, Russia \\ ${ }^{c}$ Krasnoyarsk Scientific Centre SB RAS \\ 50 Akademgorodok, Krasnoyarsk, 660036, Russia
}

Received 10.10.2015, received in revised form 16.01.2016, accepted 15.02.2016

It was shown that the early suggested method for the determination of organic acids (oxalic, tartaric, citric, malic, lactic, succinic, acetic) in wine by capillary electrophoresis technique can be used for the determination of organic acids into fruit and vegetable juices. Generally, the studied juices are found to contain citric, malic and lactic acids. The content of organic acids in the analyzing samples does not exceed the established standards of SanPiN 2.3.2.1293-03 for the food additives. The accuracy of the results of analysis was confirmed by the added-found method.

Keywords: organic acids, fruit juice, vegetable juice, capillary electrophoresis.

DOI: $10.17516 / 1998-2836-2016-9-1-100-108$.

(C) Siberian Federal University. All rights reserved

* Corresponding author E-mail address: viktoria_vs@list.ru 


\title{
Определение органических кислот
}

во фруктовых и овощных соках

методом капиллярного электрофореза

\author{
В.В. Сурсякова \\ Г.В. Бурмакина, ${ }^{\mathrm{a}, \boldsymbol{\sigma}}$, А.И. Рубайло, \\ ${ }^{a}$ Институт химии и химической технологии СО РАН \\ Россия, 660036, Красноярск, Академгородок, 50/24 \\ ${ }^{6}$ Сибирский федеральный университет \\ Россия, 660041, Красноярск, пр. Свободныій, 79 \\ ${ }^{6}$ Красноярский научный центр СО РАН \\ Россия, 660036, Красноярск, Академгородок, 50
}

Показано, что ранее предложенная методика определения органических кислот (щавелевой, винной, лимонной, яблочной, молочной, янтарной, уксусной) в винах методом капиллярного электрофореза может быть применена для определения органических кислот в овощных и фруктовых соках. Установлено, что в соках в основном содержатся лимонная, яблочная и молочная кислоты. Найдено, что их содержание не превымает нормативы СанПиН 2.3.2.129303 по пищевым добавкам. Правильность результатов анализа подтверждена методом «введено-найдено».

Ключевые слова: органические кислоты, фруктовые соки, овощные соки, капиллярный электрофорез.

\section{Введение}

Соки являются важной составляющей рациона питания человека. В состав соков входят полисахариды, минеральные вещества, органические кислоты, полифенолы и др. Органические кислоты в соках не только могут иметь естественное происхождение, но и добавляются в процессе изготовления продукции для изменения вкусовых качеств и продления срока годности. Например, лимонная кислота выступает как регулятор кислотности, антиокислитель и комплексообразователь, яблочная кислота - как регулятор кислотности, молочная кислота и ее соли - как синергисты антиокислителей. В основном состав пищевых продуктов в части содержания добавок нормируется техническими условиями. Из органических кислот в СанПиН 2.3.2.1293-03 «Гигиенические требования по применению пищевых добавок» [1] во фруктовых соках нормируется лимонная кислота (E330), содержание которой не должно превышать 3 г/л. Для ананасового сока этот СанПиН также устанавливает предельное содержание яблочной кислоты (E296) 3 г/л. Для нектаров («нектар - жидкий пищевой продукт, который не сброжен, способен к брожению, произведен путем смешивания сока, и (или) фруктового и (или) овощного пюре, и (или) концентрированного фруктового и (или) овощного пюре с питьевой водой с добавлением сахара, и (или) сахаров, и (или) меда, подсластителей или без их добавления» [2]) нормируются лимонная (Е330) и молочная (Е270) кислоты, со- 
держание которых не должно превышать 5 г/л. Технический регламент Таможенного союза на соковую продукцию из фруктов и овощей [2] устанавливает такие же нормативы предельного содержания органических кислот, но еще дополнительно содержание винной кислоты не должно превышать 4 г/л.

Для определения органических кислотах в соках предложен ряд методик. В стандартных методиках используются ферментативные и хроматографические методы [3-8]. Однако ферментативные методики для спектрофотометрического определения содержания органических кислот не являются селективными [3-6], а себестоимость анализа с использованием высокоэффективной жидкостной хроматографии (ВЭЖХ) [7-8] достаточно высока. Один из современных селективных методов анализа наряду с ВЭЖХ [9-11] - метод капиллярного электрофореза (КЭ) [12-16]. К достоинствам метода КЭ относится высокая эффективность, невысокая себестоимость анализа, возможность анализа растворов сложного состава. В большинстве методик определения органических кислот методом КЭ используются сложные по составу фоновые электролиты, включающие, как правило, различные модификаторы электроосмотического потока (ЭОП), органические амины, а в некоторых случаях добавки органических растворителей. Ввиду сложности состава такие электролиты имеют ограниченный срок хранения. В ИХХТ СО РАН в группе капиллярного электрофореза предложено вместо модификаторов ЭОП применять гидродинамическое давление для подавления электроосмотического потока [13, 17-24]. Это позволяет использовать недорогие и менее сложные по составу фоновые электролиты с большим сроком хранения.

В 2011 г. авторами была предложена методика определения алифатических органических кислот в винах методом КЭ с использованием простых по составу фоновых электролитов и гидродинамического давления для подавления ЭОП [13]. Методики определения ряда веществ в конкретном объекте не всегда подходят для определения этих же соединений в другом объекте. Например, в работе [25] показано, что разделение ЭДТА комплексов меди и железа (III) при их определении в коньяках с применением боратного фонового электролита, ранее использованнго для определения этих металлов в другом объекте, оказывается неудачным из-за мешающего влияния посторонних веществ, присутствующих в коньяках. Поэтому целью данной работы стало изучение возможности применения ранее разработанной методики определения органических кислот в винах методом КЭ для анализа овощных и фруктовых соков.

\section{Экспериментальная часть}

Измерения проводили на приборе КРЦКП СО РАН - системе капиллярного электрофореза с диодноматричным детектором Agilent ${ }^{3 \mathrm{D}} \mathrm{CE}$ G1600A (Agilent Technologies, USA). Использовали немодифицированный кварцевый капилляр с внутренним диаметром 50 мкм общей длиной 48,5 см (эффективной длиной 40 см). Капилляр термостатировали при температуре $25^{\circ} \mathrm{C}$. Детектирование проводили в УФ-области при 264 нм с опорной длиной волны 450 нм. Использовали напряжение -15 и -30 кВ. Сигнал детектора обрабатывали при помощи встроенного программного обеспечения HP ChemStation Rev.A.10.02. Ввод пробы гидродинамический при давлении 50 мбар в течение 4-20 c.

Использовали реактивы не ниже ч.д.а. Все растворы готовили с применением деионизованной воды, полученной при помощи системы очистки воды Direct-Q3 (Millipore, France), c 
электропроводностью менее $0,1 \cdot 10^{-6} \mathrm{OM}^{-1} \mathrm{~cm}^{-1}$. Использовали фоновый электролит, подобранный для определения органических кислот (щавелевой, винной, лимонной, яблочной, молочной, янтарной, уксусной) в винах методом капиллярного электрофореза с применением гидродинамического давления для подавления электроосмотического потока: 7,5 мМ м-нитробензойной кислоты, 7,5 мМ м-нитробензоата натрия, $\mathrm{pH} 3,4$ [13].

Образцы фруктовых и овощных соков фильтровали через одноразовые шприцевые фильтры с диаметром пор 0,45 мкм и разбавляли деионизованной водой. Стандартную смесь органических кислот с концентрацией каждой кислоты 1 г/л готовили растворением точных навесок всех индивидуальных кислот в деионизованной воде в мерной колбе на 1 л. Градуировочные зависимости строили в координатах: площади пиков, деленные на времена миграции, от концентрации кислот $(20,100,250,500$ и 1000 мг/л). Растворы для градуировки готовили разбавлением исходного раствора с концентрацией 1 г/л деионизованной водой. Образцы с добавлением стандартной смеси кислот готовили разбавлением деионизованной водой исходных фильтрованных образцов сока с добавкой стандартной смеси кислот (1 г/л).

Перед работой капилляр последовательно промывали 0,1 M раствором $\mathrm{NaOH}$ в течение 5 мин, затем дважды по 5 мин деионизованной водой, 12 мин - раствором фонового электролита, между анализами - раствором фонового электролита в течение 5 мин.

Поскольку направление миграции анионов и потока электролита (направление которого обращено относительно ЭОП за счет приложения гидродинамического давления) совпадает (к детектору), электрофоретическую подвижность анионов рассчитывали по уравнению

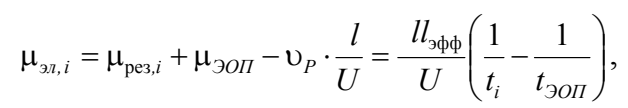

где $\mu_{\text {эл, }}$ - электрофоретическая подвижность $i$-го аналита; $\mu_{\text {рез,i }}$ - результирующая подвижность $i$-го аналита; $\mu_{\text {эоп }}$ - электроосмотическая подвижность; $v_{P}$ - скорость потока, возникающего в результате приложения гидродинамического давления; $l$ и $l_{\text {эфф }}$ - общая и эффективная длины

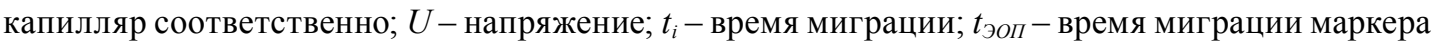
ЭОП.

\section{Результаты и их обсуждение}

Проведен анализ ряда образцов фруктовых и овощных соков на содержание органических кислоты методом КЭ, электрофореграммы изображены на рис. 1 , результаты анализа - в табл. 1. На рис. 1 видно, что происходит изменение времен миграции рассматриваемых анионов органических кислот и маркера ЭОП, поэтому идентификацию следует проводить методом добавок или по значениям их электрофоретических подвижностей (табл. 2). Как видно из табл. 2, электрофоретические подвижности анионов органических кислот в стандартной смеси и в реальных объектах имеют близкие значения с учетом доверительного интервала, следовательно, матрица реального объекта не приводит к сдвигу $\mathrm{pH}$ фонового электролита и не влияет на подвижности. Изменение времен миграции обусловлено исключительно изменением скорости ЭОП.

Результаты анализа соков, представленные в табл. 1, показывают, что в основном в соках содержатся лимонная, яблочная и молочная кислоты. Найдено, что их содержание не пре- 
Таблица 1. Концентрации органических кислот в исследованных образцах $(\mathrm{n}=3, \mathrm{P}=0.95)$

\begin{tabular}{|c|c|}
\hline Кислота & $\mathrm{C} \pm \Delta \mathrm{C}$, г/л \\
\hline \multicolumn{2}{|c|}{ Яблочный сок «Добрый» } \\
\hline Яблочная & $4,2 \pm 0,5$ \\
\hline Молочная & $0,21+0,02$ \\
\hline \multicolumn{2}{|c|}{ Вишневый сок «Моя семья» } \\
\hline Лимонная & $2,7 \pm 0,3$ \\
\hline Яблочная & $4,2 \pm 0,4$ \\
\hline Молочная & $0,070 \pm 0,006$ \\
\hline \multicolumn{2}{|c|}{ Томатный сок «Добрый» } \\
\hline Лимонная & $3,8 \pm 0,6$ \\
\hline Яблочная & $0,38 \pm 0,09$ \\
\hline Молочная & $0,13 \pm 0,02$ \\
\hline
\end{tabular}
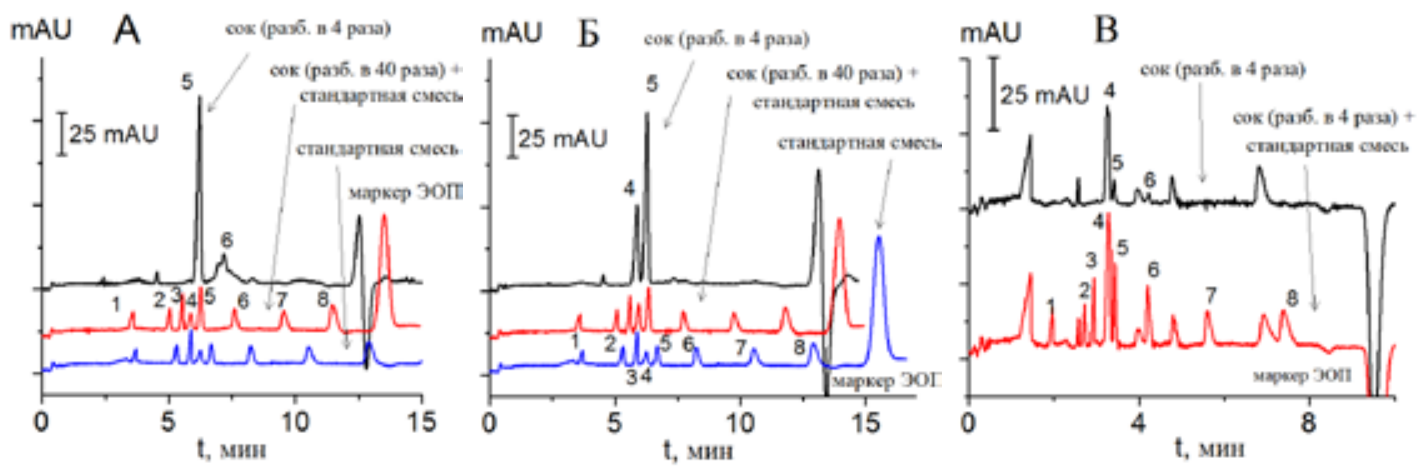

Рис. 1. Электрофореграммы разделения соков, стандартной смеси органических кислот и соков с добавкой стандартной смеси кислот (100 мг/л): А) яблочный, Б) вишневый, В) томатный соки. Пики анионов кислот: 1 - щавелевая, 2 - винная, 3 - муравьиная, 4 - лимонная, 5 - яблочная, 6 - молочная, 7 - янтарная, 8 - уксусная

вышает нормативы СанПиН 2.3.2.1293-03 по пищевым добавкам. Для проверки правильности методики использован метод «введено-найдено». Как видно из данных табл. 3, полученные результаты подтверждают отсутствие значимой систематической погрешности.

Таким образом, показано, что ранее предложенная методика для определения органических кислот в винах методом капиллярного электрофореза может быть применена для определения органических кислот в овощных и фруктовых соках. 
Таблица 2. Электрофоретические подвижности анионов органических кислот в стандартной смеси и реальных объектах $(\mathrm{n}=3, \mathrm{P}=0,95)$

\begin{tabular}{|l|c|c|c|c|}
\hline \multirow{2}{*}{ Кислота } & \multicolumn{3}{|c|}{ Электрофоретическая подвижность $\mu_{э л}, 10^{-9} \mathrm{M}^{2} \mathrm{~B}^{-1} \mathrm{c}^{-1}$} \\
\cline { 2 - 5 } & Стандартная смесь & Яблочный сок & Вишневый сок & Томатный сок \\
\hline Щавелевая & $42.6 \pm 0.7$ & $42.5 \pm 0.7$ & $42.8 \pm 0.7$ & $41.9 \pm 0.6$ \\
\hline Винная & $25.7 \pm 0.5$ & $25.8 \pm 0.4$ & $26.0 \pm 0.5$ & $25.7 \pm 0.5$ \\
\hline Муравьиная & $22.0 \pm 0.4$ & $22.0 \pm 0.4$ & $22.1 \pm 0.2$ & $21.9 \pm 0.3$ \\
\hline Лимонная & $19.9 \pm 0.4$ & $20.0 \pm 0.4$ & $20.0 \pm 0.5$ & $19.6 \pm 0.4$ \\
\hline Яблочная & $17.8 \pm 0.4$ & $17.8 \pm 0.2$ & $17.9 \pm 0.3$ & $17.8 \pm 0.3$ \\
\hline Молочная & $11.9 \pm 0.3$ & $12.0 \pm 0.3$ & $11.9 \pm 0.2$ & $12.2 \pm 0.3$ \\
\hline Янтарная & $6.4 \pm 0.1$ & $6.4 \pm 0.1$ & $6.4 \pm 0.1$ & $6.5 \pm 0.2$ \\
\hline Уксусная & $2.7 \pm 0.1$ & $2.7 \pm 0.1$ & $2.7 \pm 0.1$ & $2.8 \pm 0.1$ \\
\hline
\end{tabular}

Таблица 3. Результаты определения (мг/л) органических кислот методом «введено-найдено» $(\mathrm{n}=3$, $\mathrm{P}=0,95)$. Яблочный и вишневый сок разбавлены в 40 раз, томатный - в 4 раза

\begin{tabular}{|l|c|c|c|c|}
\hline \multirow{2}{*}{ Кислота } & \multirow{2}{*}{ Введено } & \multicolumn{3}{|c|}{ Найдено } \\
\cline { 2 - 5 } & & Яблочный сок & Вишневый сок & Томатный сок \\
\hline Щавелевая & 100 & $107 \pm 9$ & $105 \pm 12$ & $89 \pm 15$ \\
\hline Винная & 100 & $103 \pm 5$ & $107 \pm 9$ & $108 \pm 9$ \\
\hline Муравьиная & 100 & $105 \pm 8$ & $100 \pm 4$ & $107 \pm 8$ \\
\hline \multirow{2}{*}{ Лимонная } & 0 & - & $68 \pm 8$ & $959 \pm 146$ \\
\hline \multirow{2}{*}{ Яблочная } & 100 & $111 \pm 11$ & $176 \pm 15$ & $1050 \pm 98$ \\
\hline \multirow{2}{*}{ Молочная } & 0 & $105 \pm 13$ & $105 \pm 10$ & $94 \pm 23$ \\
\hline & 100 & $205 \pm 13$ & $215 \pm 29$ & $207 \pm 21$ \\
\hline Янтарная & 0 & $5.3 \pm 0.5$ & $1.7 \pm 0.2$ & $34 \pm 5$ \\
\hline Уксусная & 100 & $102 \pm 4$ & $103 \pm 8$ & $127 \pm 11$ \\
\hline
\end{tabular}

\section{Список литературы}

1. СанПиН 2.3.2.1293-03. Гигиенические требования по применению пищевых добавок. М.: Минздрав, 2003. 230 c. [SanPiN 2.3.2.1293-03. Hygienic regulations for application of food additives. Moscow: Minzdrav, 2003, 230 p. (In Russ.)]

2. ТР ТС 023/2011. Технический регламент на соковую продукцию из фруктов и овощей. URL: http://www.eurasiancommission.org/ru/act/texnreg/deptexreg/tr/Documents/TR\%20TS\%20 SokovayaProd.pdf (дата обращения: 14.04.2016) [TR TU 023/2011 Technical regulations on fruit and vegetables juice products. URL:http:/www.eurasiancommission.org/ru/act/texnreg/deptexreg/tr/ Documents/ TR\%20TS\%20SokovayaProd.pdf (date of the application: 14.04.2016) (In Russ.)]

3. ГОСТ Р 51129-98. Соки фруктовые и овощные. Метод определения лимонной кислоты. M: Госстандарт, 1998. 8 с. [GOST R 51129-98. Fruit and vegetable juices. Method for determination of citric acid (citrate). Moscow: Gosstandard, 1999, 8 p. (In Russ.)] 
4. ГОСТ P 51239-98. Соки фруктовые и овощные. Метод определения L-яблочной кислоты. M: Госстандарт, 1998. 8 с. [GOST R 51239-98. Fruit and vegetable juices. Method for determination of L-malic acid content. Moscow: Gosstandard, 1998, 8 p. (In Russ.)]

5. ГОСТ Р 51441-99. Соки фруктовые и овощные. Ферментативный метод определения содержания уксусной кислоты (ацетата) с помощью спектрофотометрии. М: Госстандарт, 1999. 10 c. [GOST R 51441-99. Fruit and vegetable juices. Enzymatic method for spectrophotometric determination of acetic acid (acetate) content. Moscow: Gosstandard, 1999, 10 p. (In Russ.)]

6. СТБ EN 12631-2007. Соки фруктовые и овощные. Ферментативный метод определения содержания D и L-молочной кислоты (лактата) с помощью спектрометрии с использованием NAD. Минск: Госстандарт, 18 с. [STB EN 12631-2007. Fruit and vegetable juices. Enzymatic method of determination of D- and L-lactic acid (lactate) content - NAD spectrometric method. Minsk: Gosstandard, 2007, 18 p. (In Russ.)]

7. ГОСТ Р 51428-99. Соки фруктовые. Метод определения содержания винной кислоты с помощью высокоэффективной жидкостной хроматографии. М: Госстандарт России, 1999. 6 c. [GOST R 51428-99. Fruit juices. Method for determination of tartaric acid content using high performance liquid chromatography. Moscow: Gosstandard, 1999, 7 p. (In Russ.)]

8. ГОСТ Р 54684-2011. Продукция соковая. Определение органических кислот методом обращенно-фазовой высокоэффективной жидкостной хроматографии. М: Стандартинформ, 2012. 20 c. [GOST R 54684-2011. Fruit juices. Determination of organic acids by high performance liquid chromatography (HPLC). Moscow: Standardinform, 2012, 20 p. (In Russ.)]

9. Amelin V.G., Podkolzin I.V., Tretiakov A.V. Determination of organic acids in alcoholic and nonalcoholic beverages by reversed-phase high-performance liquid chromatography. Journal of Analytical Chemistry. 2012. Vol. 67(3), P. 262-268.

10. Захарова А.М., Карцова Л.А., Гринштейн И.Л. Определение органических кислот, углеводов и подсластителей в пищевых продуктах и биологически активных добавках методом высокоэффективной жидкостной хроматографии. Аналитика и контроль. 2013. Т. 17(2), С. 204-210. [Zaharova A.M., Kartsova L.A., Greenstein I.L. Determination of organic acids, carbohydrates and sweeteners in food products and biologically active additives by HPLC. Analytics and control. 2013. Vol. 17(2), P. 204-210. (In Russ.)]

11. Scherer R., Rybka A.C.P., Ballus C.A., Meinhart A.D., Filho J.T., Godoy H.T. Validation of a HPLC method for simultaneous determination of main organic acids in fruits and juices. Food Chemistry 2012. Vol. 135, P. 150-154.

12. Golubenko A.M., Nikonorov V.V., Nikitina T.G. Determination of hydroxycarboxylic acids in food products by capillary electrophoresis. Journal of Analytical Chemistry. 2012. Vol. 67(9), P. 778782 .

13. Сурсякова В.В., Попова О.В., Бурмакина Г.В., Рубайло А.И. Новая методика определения органических кислот в винах методом капиллярного электрофореза. Журнал Сибирского федерального университета. Химия. 2011. T. 4(4), С. 393-400. [Sursyakova V.V., Popova O.V., Burmakina G.V., Rubaylo A.I. Novel method for determination of organic acids in wine using capillary electrophoresis. Journal of Siberian Federal University. Chemistry. 2011. Vol. 4(4), P. 393-400. (In Russ.)] 
14. Klampfl C.W. Determination of organic acids by CE and CEC methods. Electrophoresis 2007, Vol. 28, P. 3362-3378.

15. Navarro-Pascual-Ahuir M., Lerma-García M.J., Simó-Alfonso E.F., Herrero-Martínez J.M. Quality control of fruit juices by using organic acids determined by capillary zone electrophoresis with poly(vinyl alcohol)-coated bubble cell capillaries. Food Chemistry. 2015, Vol. 188, P. 596-603.

16. Liu F.-J., Ding G.-S., Tang A.-N. Simultaneous separation and determination of five organic acids in beverages and fruits by capillary electrophoresis using diamino moiety functionalized silica nanoparticles as pseudostationary phase. Food Chemistry. 2014, Vol. 145, P. 109-114.

17. Сурсякова В.В., Калякин С.Н., Бурмакина Г.В., Рубайло А.И. Использование внутреннего стандарта при определении анионов методом капиллярного электрофореза с косвенным спектрофотометрическим детектированием. Журнал Сибирского федерального университета. Химия. 2009. T. 2(1), C. 42-47. [Sursyakova V.V., Kalyakin S.N., Burmakina G.V., Rubaylo A.I. The using of internal standard in determination of anions by capillary electrophoresis technique with indirect spectrophotometric detection. Journal of Siberian Federal University. Chemistry. 2009. Vol. 2(1), P. 42-47. (In Russ.)]

18. Сургутскова А.Г., Бурмакина Г.В., Сурсякова В.В., Рубайло А.И. Применение метода высокоэффективного капиллярного электрофореза для мониторинга анионного состава пресноводных экосистем на примере реки Енисея. Журнал Сибирского федерального университета. Химия. 2009. T. 2(3), C. 266-274. [Surgutskova A.G., Burmakina G.V., Sursyakova V.V., Rubaylo A.I. The using of high-performance capillary electrophoresis technique for monitoring of freshwater ecosystems by example river Yenisei. Journal of Siberian Federal University. Chemistry. 2009. Vol. 2(3), P. 266-274. (In Russ.)]

19. Бондарева Л.Г., Калякина О.П., Бурмакина Г.В., Сурсякова В.В., Калякин С.Н., Рубайло А.И. Исследование анионного состава объектов окружающей среды промышленной зоны г. Красноярска методами ионной хроматографии и капиллярного электрофореза. Журнал Сибирского федерального университета. Химия. 2009. Т. 2(4), C. 368-376. [Bondareva L.G., Kalyakina O.P., Burmakina G.V., Sursyakova V.V., Kalyakin S.N., Rubailo A.I. The Study of anionic composition of the environment of the Krasnoyarsk's industrial zone by ion chromatography and capillary electrophoresis. Journal of Siberian Federal University. Chemistry. 2009. Vol. 2(4), P. 368-376. (In Russ.)]

20. Sursyakova V.V., Bondareva L.G., Burmakina G.V., Rubailo A.I. New approaches to identification of sources of phenols in surface water bodies. Doklady Chemistry. 2011. Vol. 441(2), P. 379-382.

21. Kalyakin S.N., Sursyakova V.V., Burmakina G.V., Rubailo A.I. Hydrodynamic suppression of the electroosmotic flow in capillary electrophoresis with indirect spectrophometric detection. Journal of Analytical Chemistry. 2009. Vol. 64(4), P. 398-403.

22. Sursyakova V.V., Kalyakin S.N., Burmakina G.V., Rubaylo A.I. System peaks in capillary zone electrophoresis of anions with negative voltage polarity and counter-electroosmotic flow. Electrophoresis. 2011. Vol. 32(2), P. 210-217.

23. Sursyakova V.V., Kalyakin S.N., Burmakina G.V., Rubaylo A.I. System peaks and optimization of anion separation in capillary electrophoresis with non-reversed electroosmotic flow. Journal of Analytical Chemistry. 2012. Vol. 67(9), P. 783-789.

$$
-107-
$$


24. Sursyakova V.V., Rubaylo A.I. New peak broadening parameter for the characterization of separation capability in capillary electrophoresis. Journal of Separation Science. 2015. Vol. 38(4), P. 690-696.

25. Popova O.V., Sursyakova V.V., Burmakina G.V., Rubaylo A.I. Determination of iron and copper ions in cognacs by capillary electrophoresis. Journal of Analytical Chemistry. 2015. Vol. 70(2), P. 198-202. 